\title{
Ultrastructure of Terminal Pulpal Blood Vessels in Mouse Molars '
}

\author{
RICHARD E. CORPRON, JAMES K. AVERY AND SOO D. LEE \\ School of Dentistry, The University of Michigan, \\ Ann Arbor, Michigan 48104
}

\begin{abstract}
The purpose of this investigation was to study the fine structure of pulpal capillaries located in the odontoblastic layer and immediate subjacent zone. The observations were from first molars of white mice sacrificed at five day intervals from 25-90 days. Both capillaries and small vessels with an incomplete smooth muscular coating appeared in the zone subjacent to the odontoblastic layer from 25-60 days. At the same time, capillaries which exhibited intracellular fenestrations in the endothelial wall were located within the odontoblastic layer.

From 50-90 days, the capillaries among odontoblasts, especially at the pulpal horns, appeared close to the predentinal surface, and an isolated capillary appeared to extend into predentin and run parallel to the outer surface of the odontoblastic layer for a short distance. At these ages, the capillaries subjacent to the odontoblastic layer also exhibited fenestrations along the thin endothelial walls similar to those observed at earlier ages in capillaries among odontoblasts.
\end{abstract}

The vascular supply of the odontogenic zone of the dental pulp is of interest, since it supplies those cells responsible for the development and reparative processes of the dentin. Knowledge to date regarding the arrangement and structure of the terminal capillaries among odontoblasts has been derived from histological observations of a wide variety of species studied at various stages of development (Kramer, '60; Bernick, '60; Adams, '59, '62; Provenza, '58; Jesson, '67 and James, '55), and some differences in the morphology of pulpal capillaries have appeared related to both species-to-species and stage of development variations. The vascular supply among the odontoblasts has also been described in the continuously growing rodent incisor (James, '55; Adams, '59) - a phenomenon of dental growth without analogy in many mammalian species including human.

The ultrastructure of pulpal capillaries has been reported in several species of mammal by Matthews, Dorman and Bishop ('59), Han and Avery ('63), Riedel, Fromme and Tallen ('66), and Kukletova ('70) who reported cellular specializations which appear to contribute to transendothelial transport. Although the pinocytotic microvesicles frequently have been reported present in capillary walls, only Riedel et al. ('66) reported three types of capillaries, one of which exhibited intracellular fenestrations or pores. The ultrastructural study of Takuma and Nagai (71) revealed capillaries located among the odontoblast.

Since there are wide variations in the organization and structure of capillaries from tissues in different regions of the body (Farquhar, '61; Majno, '65), it is the purpose of the present study to investigate the fine structure of capillaries located in the odontoblastic layer and immediate subjacent zones. Teeth which are in functional occlusion will be utilized for all such observations.

\section{METHODS AND MATERIALS}

Mandibular first molars were used from groups of five Swiss-Webster white mice sacrificed at five day intervals from 25-90 days. Fixation was carried out using $1.33 \%$ osmic acid buffered with s-collidine at $\mathrm{pH} 7.4$ with $5 \%$ sucrose added to obtain

Received Nov, 30, '73. Accepted Feb. 5, '74.

1 This project was supported by USPHS Research Grant DE 01604 from the National Institute of Dental Research, National Institutes of Health, Bethesda, Maryland. 
an isotonic solution. The apical one third of the roots was removed and the teeth were fixed for two hours at $4^{\circ} \mathrm{C}$. The specimens were next washed in distilled water, dehydrated in a series of graded ethyl alcohols, passed through two changes of propylene oxide, transferred to $50 \%$ propylene oxide and $50 \%$ Epon 812 , and finally embedded one hour later in Epon 812 in Beem Capsules. The blocks were placed in an oven at $37^{\circ} \mathrm{C}$ overnight, $45^{\circ} \mathrm{C}$ on the following day, and $60^{\circ} \mathrm{C}$ overnight. Thick sections $(1 \mu)$ were produced and stained with methylene blue for orientation, and ultrathin sections were prepared from the molars with an LKB ultramicrotome equipped with a DuPont diamond knife. The sections were stained with aqueous uranyl acetate and photographed with an Hitachi HS 8 electron microscope. Observations were made from 9-10 teeth from each age of animal.

\section{RESULTS}

The present observations were made from coronal pulp and adjacent dentin of teeth in functional occlusion, which at about 25 days for first molars of mice (Corpron and Avery, '73). From 25 to 60 days, both capillaries and small vessels with an incomplete muscular coating were observed in the loosely arranged subodontoblastic layer (fig. 1). Arterioles and venules were rarely observed immediately subjacent to the odontoblasts. Capillaries were most numerous in the pulpal horns and appeared as endothelial cell lined channels (8-10 microns in diameter). The wall of the endothelial cell was very thin on the side opposite the irregularly shaped nucleus, which projected into the Iumen. Intracytoplasmic contents of the endothelial cells included several elements of rough endoplasmic reticulum, occasional small, round mitochondria, and frequent pinocytotic microvesicles. The microvesicles were most numerous in the thick segment of the endothelial cell and in the perinuclear location. Where two endothelial cells contacted, they were typically overlapped to a varying degree (fig. 5). Along this line of contact areas of increased density of the apposed cellular membranes appeared, which were separated by a space of approximately $200 \AA$.
Such specialized regions of intercellular attachment resemble the zonula occludens (Farquhar and Palade, '63). A continuous basement lamina enclosed the periphery of the capillary and separated the wall of the endothelial cell from thin extensions of pericytes which usually only partially surrounded the capillary (fig. 5).

Precapillary vessels were observed in the subodontoblastic layer, and these vessels differed from the capillaries by displaying thicker endothelial cell walls and an incomplete smooth muscular coating. The muscular layer was separated from the endothelial layer by a thick basement lamina (300-500 $\AA$ ) which surrounded the endothelial cells, and the muscular coating was in turn completely covered externally by a separate basement lamina which appeared continuous with the inner basement lamina where the muscular coating was absent (figs. 1,3). Occasionally, the relationship of the outer endothelial cell wall was one of close approximation ( $200-300 \AA$ ) to the surrounding smooth muscle wall with an absence of a separating basement lamina in what area (fig. 3). Such a relationship resembles the myoendothelial junctions suggested by Rhodin ('67). The muscular coated vessels were usually in close approximation to both myelinated and small nonmyelinated nerve endings (fig. 3), which were separated from this smooth muscle by the outer basement lamina which also was noted by Matthews, Dorman and Bishop ('59).

From 25 to 50 days, small capillaries were observed to extend varying depths in the odontoblastic layer, especially at the pulpal horns (fig. 2). Usually the capillaries were located in the more basal portion of the odontoblastic layer in the younger teeth (25-40 days), and more frequently approximated the predentinal surfaces in the pulpal horns of the teeth of 50 days and older. At the extreme tip of the pulpal horns, an occasional marginal capillary appeared close to the predentinal surface. The ultrastructure of such vessels in the odontoblastic layer revealed a small lumen usually the size of one erythrocyte. The intracytoplasmic structures were similar to those of the capillaries located in the subodontoblastic 
layer. Along the cellular wall of the more flattened side of the capillaries of opposite the endothelial cell nucleus, occasional pores or fenestrations appeared (figs. 5, 5a). These pores were characterized by a $300-500 \AA$ opening in the cell wall which was bridged by a thin membrane which appeared to be continuous on either side of the pore with the endothelial cell wall. The number and distribution of fenestrations were variable from one segment of the capillary wall to another. The periphery of these fenestrated capillaries was enclosed by a continuous basement lamina which separated the outer membrane of the endothelial cell from the thin extensions of the pericytes or adjacent odontoblasts. These capillaries were not encircled completely by the processes of the pericytes and were classified as A-2- $\alpha$ capillaries (Bennett et al., '59).

From 50-90 days, the capillaries located in the odontoblastic layer, especially in the pulpal horns and along the roof of the pulp chamber frequently appeared close to the predentinal surface (fig. 4). At the tip of the pulp horn an isolated capillary was observed to extend into predentin and run parallel to the outer surface of the odontoblastic layer for a short distance (fig. 6). This capillary appeared completely surrounded by a basement lamina which separated the endothelial wall from the predentin. The lumen had remained patent and was approximately the diameter of one erythrocyte. The endothelial cell wall was rather thin and contained correspondingly few intracytoplasmic organelles. Occasional fenestrations were observed along the endothelial wall (fig. 6a).

In the 50-90 day animals the capillaries subjacent to the odontoblastic layer exhibited pores which were similar in size and location to those observed at the earlier ages in capillaries among the odontoblast (figs. 5, 5a, 7).

\section{DISCUSSION}

The dental pulp is a unique tissue because of its inclusion within a hard tissue capsule of dentin. The flow of blood to the pulp is an important factor in the maintenance of pulpal vitality and in support of dentinal apposition and reparative responses to trauma or injury. Provenza
('58) observed that the major blood vessels in the human pulp did not exceed the size of arterioles $(100 \mu)$ and thus the pattern of efferent vessels of the dental pulp is characterized by a gradation of vessels from the arteriole to metarteriole, precapillary, and the true capillary. Arteriovenous anastomoses also are present in the pulp according to Provenza. The flow of blood from the arteriole to the capillary bed is modified by contraction and relaxation of smooth muscle cells in the walls of the arteriole, metarteriole and precapillary sphincters. The major exchange of substances between the blood and the surrounding tissues occurs primarily at the level of the capillary bed or in small venules (Copenhaver, Bunge and Bunge, '71). The microcirculatory bed is considered as the area in which blood flows through the terminal capillary system and is that ultimate portion of the vascular system concerned with the transfer of gases and nutrients and the removal of metabolic waste products (Majno, '65). The precapillary sphincters are included in the microcirculatory bed, but the capillaries are the major component (Wiedeman, '63).

The morphology of the blood vessels of the "microcirculation" (Fulton, '57) of the dental pulpal tissue provides important insight into potential mechanism of transendothelial transport of nutrients to the odontogenic zone, namely the odontoblastic layer and the immediately subjacent zone which contains the subodontoblastic plexuses of nerves and blood vessels.

Prior to gaining the resolving power and magnification of the electron microscope, few differences were described in the smaller blood vessels of the various tissues and organs. It was commonly assumed that most of the capillaries were structurally similar. But, as the details of the fine structure of capillaries from a variety of tissues and regions of the body were observed, it became evident that there were a number of different kinds of vessels structurally adapted to the physiologic requirements of individual tissues, Bloom and Fawcett, '68; Farquhar, '61; Majno. '65; Rhodin. '62, '67; Karnovsky, '67; Bruns and Palade, '68a,b). This range in variation of the morphology of the capillary and their investing structures led to a 
morphologic classification by Bennett et al. ('59) based upon the presence or absence of an investing basement lamina, intra- or intercellular fenestrations, and pericapillary cellular investment and these structural elements appeared to contribute to the capillary permeability.

The pulpal capillaries in this study exhibited little variation in the surrounding basement lamina and pericapillary cellular investment, but the variations in the endothelial cell structures related to capillary permeability were of interest. Three of the possible pathways of transendothelial transport in capillaries (Majno, '65) have been reported as: (1) Intercellular gaps; (2) Micropinocytotic vesicles and (3) Fenestrations. The endothelial fenestrations are a controversial finding in dental pulpal capillaries. Han and Avery ('63) did not observe fenestrations in pulpal capillaries of guinea pigs, but Riedel et al. ('66) reported one of three types of pulpal capillaries in humans exhibited these pores. Kukletova ('70) noted that fenestrations were lacking in the dental pulps of calves. In the present study, fenestrations appeared more numerous with age (fig. 7) and were located where the endothelial wall was very thin and contained only sparse micropinocytotic vesicles (fig. 7). The distribution spread from peripheral location in capillaries among odontoblasts ultimately to include the capillaries in the subodontoblastic area in older animals (figs. 5, 5a, 7). Throughout the body, capillaries in smooth and cardiac muscles have appeared devoid of fenestration, but tissues involved in rapid fluid transport such as kidney, digestive tract, and the endocrine glands exhibit capillary fenestration (Bloom and Fawcett, '68). A similar functional relationship may be ascribed to fenestrations in capillaries within the odontoblastic layer which must supply the products for both the predentinal matrix formation and the subsequent processes of calcification and maturation. A similar function of rapid exchange was attributed by Garant and Gillespie ('69) to fenestrated capillaries of the papillary layer during calcification and maturation of enamel. It could be speculated that in the process of rapid formation of reparative dentin in response to injury, fenestrations could serve as important pathways of transport of metabolites across the capillary endothelium.

Although the presence of a functional capillary enclosed within the predentin at the cuspal tips occurred occasionally in the more mature animals (fig. 6), the entrappment of the vessel at that predentinal location probably resulted from a differential regression of the odontoblasts and the interodontoblastic capillaries from the predentinal surface as compared to the younger ages.

Myoendothelial junctions were located only in the precapillary vessels in which the investing smooth muscle was an interrupted or incomplete layer surrounding the endothelial cell (fig. 3 ). Such observations compare to similar structures observed in the terminal arterioles of the periodontal ligament in humans (Griffin and Spain, '72). Rhodin ('67) postulated that the myoendothelial junction served to stabilize the endothelial wall. In support of this theory is the fact that such junctions did not appear in arterioles with a well developed elastica interna or where the media consisted of several muscular layers. Thus. the thinner the vascular wall, the greater is the need for the firm relationship of the endothelium and the smooth muscular media.

An additional function attributed to the myoendothelial junctions is a pathway for the exchange of metabolities between the endothelial cell and the investing smooth muscle layer. Rhodin ('67) postulated that the myoendothelial junctions served as a conduction device for humeral transmitter substances picked up by the luminal cell membrane of the endothelial cell and passed onto the investing smooth muscle cell across the myoendothelial junctions. This functional implication of the myoendothelial junction remains speculative but whatever the role of such junctions, their distribution in this study appeared limited to the precapillary vessels.

\section{LITERATURE CITED}

Adams, D. 1959 Peripheral capillaries in the rodent incisor pulp. J. Dent. Res., 38: 969-978. 1962 The blood supply to developing dentine. Arch. Oral Biol., 7: 773-774.

Bennet, H. S., J. H. Luft and J. Hampton 1959 
Morphological classification of vertebrate blood capillaries. Amer. J. Physiol., 196: 381-390.

Bernick, S. 1960 Vascular supply to the developing teeth in rats. Anat. Rec., 137: 141-151.

Bloom, W., and D. W. Fawcett 1968 A Textbook of Histology. 9th ed., W. B. Saunders Co., Philadelphia, pp. 358-389.

Bruns, R. R., and G. E. Palade 1968a Studies on blood capillaries. I. General organization of blood capillaries in muscle. J. Cell Biol., 37: 244-276.

- 1968b Studies on blood capillaries. II. Transport of ferritin molecules across the wall of muscle capillaries. J. Cell Biol., 37: 277-299.

Copenhaver, W. M., R. P. Bunge and M. B. Bunge 1971 Bailey's Textbook of Histology, 16th ed. Williams and Wilkins Co., Baltimore, pp. 305-319.

Corpron, R. E., and J. K. Avery 1973 The ultrastructure of intradentinal nerves in developing mouse molars. Anat. Rec., 175: 586-606.

Farquhar, M. G. 1961 Fine structure and function of capillaries of the anterior pituitary gland. Angiology, 12: 270-292.

Farquhar, M. G., and G. E. Palade 1963 Junctional complexes in various epithelia. J. Cell Biol., 17: 375-412.

Fulton, G. P. 1957 Microcirculatory terminology. Angiology, 8: 102-104.

Garant, P. R., and R. Gillispie 1969 The presence of fenestrated capillaries in the papillary layer of the enamel organ. Anat. Rec., 163: $71-80$.

Griffin, C. J., and H. Spain 1972 Orientation and vasculature of human periodontal ligament mechanoreceptors. Arch. Oral Biol., 17: 913921.

Han, S. S., and J. K. Avery 1963 The ultrastructure of capillaries and arterioles of hamster dental pulp. Anat. Rec., 145: 549-572.

James, W. W. 1955 The blood capillary system of the odontoblast layer of the dental pulp. J. Anat., 89: 547-549.

Jesson, H. 1967 The ultrastructure of odonto- blasts in perfusion fixed, demineralized incisors of adult rats. Acta Odontol. Scand., 25: 491523.

Karnovsky, M. J. 1967 The ultrastructural basis capillary permeability studied with peroxidase as a tracer. J. Cell Biol., 35: 213-236.

Kramer, I. R. H. 1960 The vascular architecture of the human dental pulp. Arch. Oral Biol., 2: 177-189.

Kukletova, M. 1970 Submicroscopic structure of blood vessels in calf dental pulp. Scripta Medica., 43: 109-116.

Matthews, J. L., H. I. Dorman and J. G. Bishop 1959 Fine structure of the dental pulp. J. Dent. Res., 38: 940-946.

Majno, G. 1965 Ultrastructure of the vascular membrane. In: Handbook of Physiology, Circulation, W. F. Hamilton and P. Dow, eds., Section 2, Vol. III, American Physiological Society, Washington, D. C., pp. 2293-2375.

Provenza, V. 1958 The blood supply of the dental pulp with emphasis on capillary circulation. Circulation Res., 6: 213-218.

Riedel, H., H. G. Fromme and B. Tallen 1966 Elektronenmikroskophische untersuchengen zur frage der kapillarmorphologie in der menschlichen zahnpulpa. Arch. Oral Biol., 11: 1049-1055.

Rhodin, J. A. G. 1967 The ultrastructure of mammalian arterioles and precapillary sphinctors. J. Ultrastructure Res., 18: 181-223. 1962 The diaphragm of capillary endothelial fenestrations. J. Ultrastructure Res., 6: 171-185.

Takuma, S., and N. Nagai 1971 Ultrastructure of rat odontoblasts in various stages of their development and maturation. Arch. Oral Biol., 16: 993-1011.

Wiedeman, M. P. 1963 Patterns of arteriovenous pathways. In: Handbook of Physiology, Circulation. W. F. Hamilton and P. Dow, eds., Section 2, Vol. II, American Physiological Society, Washington, D. C., p. 891 . 


\section{Abbreviations}
A, Axon
MN, Myelinated nerve
BL, Basement lamina
OD, Odontoblast
C, Capillary
CL, Capillary lumen
PC, Pericyte
D, Dentin
P, Precapillary
EC, Endothelial cell
$P D$, Predentin
F, Fibroblast
RBC, Erythrocyte

PLATE 1

EXPLANATION OF FIGURE

1 Sixty days. This section is predominately from the subodontoblastic region along the lateral wall of coronal pulp. A small area of calcifying dentin (D) and predentin appear at the upper right. The odontoblastic layer (OD) contains a small capillary (C) at the basal portion subjacent to the odontoblastic layer. The subodontoblostic neural plexus of both myelinated nerves (MN) and non-myelinated nerves appear and several precapillary vessels (P) accompany the nerves. $\times 2200$. 


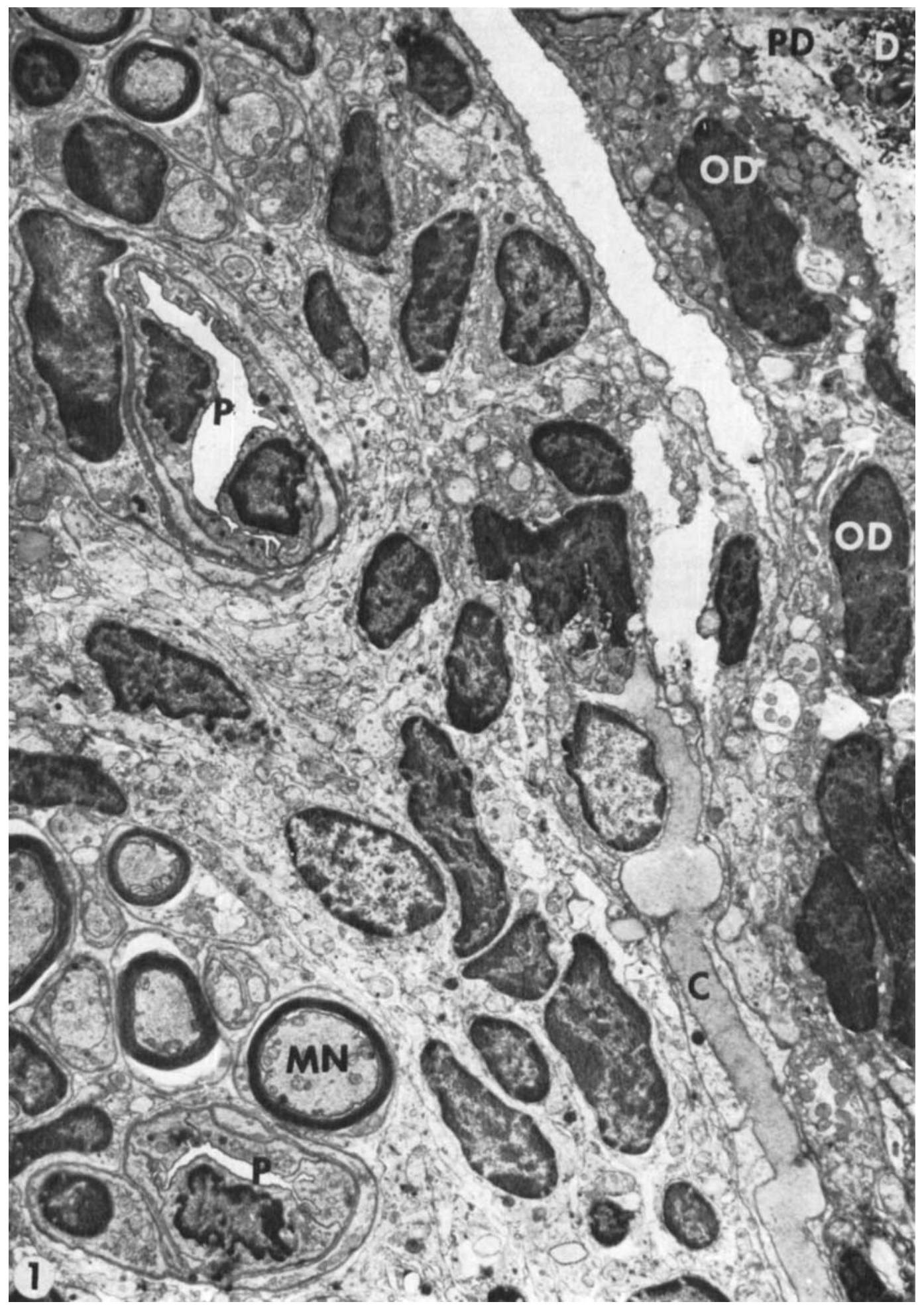


PLATE 2

EXPLANATION OF FIGURES

2 Forty-five days. A capillary (C) is located among odontoblasts (OD) in the basal portion of the odontoblastic layer. Both predentin (PD) and dentin (D) appear at the right. $\times 3300$.

3 Forty days. A small precapillary is located in the subodontoblastic area. Several small nerves which appear as free axons (A) are located adjacent to this vessel. The vessel exhibits a continuous endothelial cell (EC) lamina, which is surrounded incompletely by a layer of smooth muscle (SM). The endothelial cells are separated from the muscular layer by a thick basement lamina which is obscure or absent in isolated areas (solid arrows). The muscular layer is covered externally by a separate basement lamina which is continuous to the inner lamina where the muscular layer is absent. An occasional finger-like extension of the endothelial cell (hollow arrow) appears interdigitated with the smooth muscle. $\times 20,000$. 

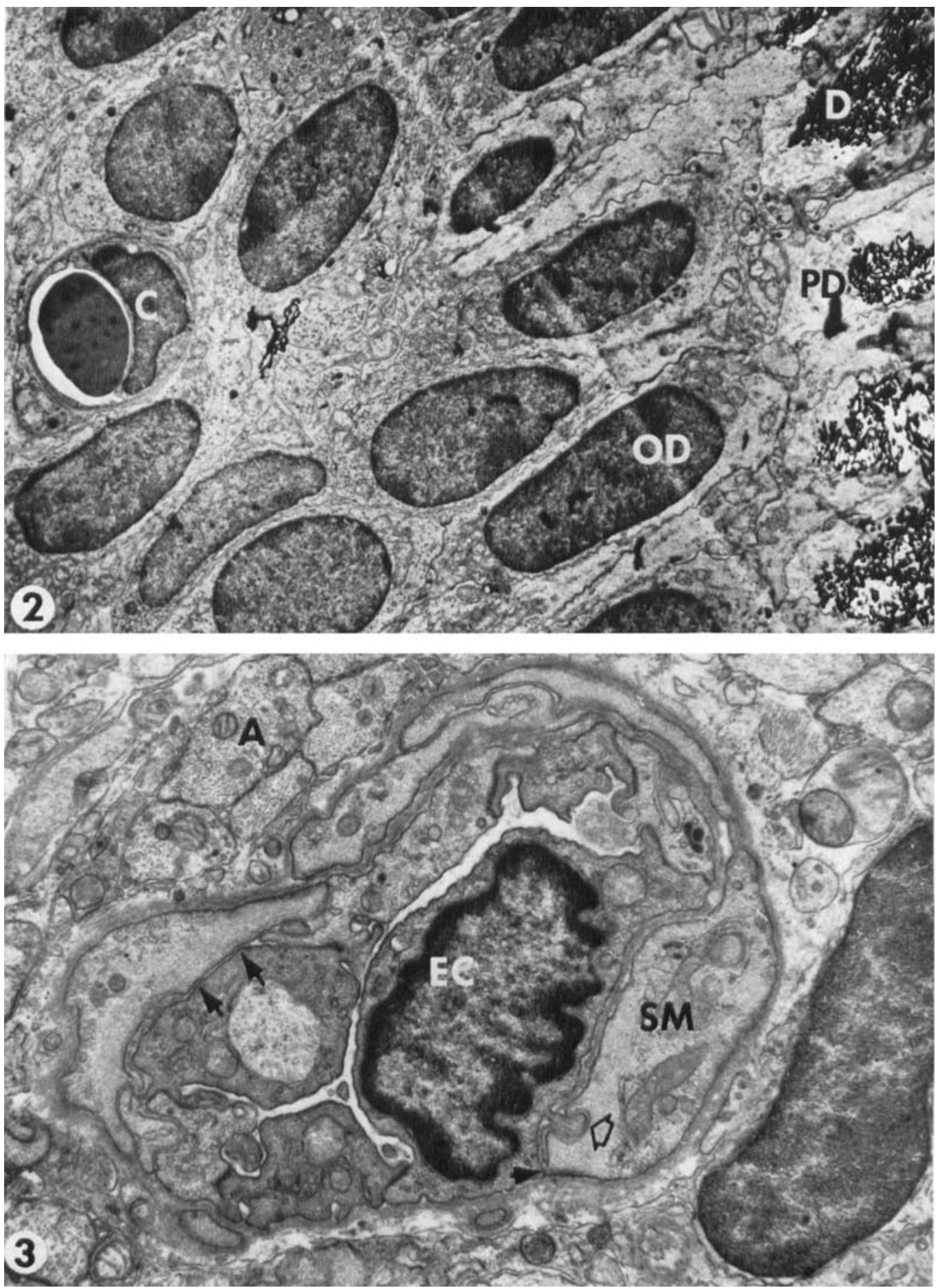


\section{PLATE 3}

EXPLANATION OF FIGURES

4 Fifty days. This section from the tip of a pulpal axon. A portion of the odontoblastic layer with a capillary (C) is located among the odontoblasts (OD) in close proximity to the predentin (PD). Several intradentinal nerves (arrows) appear in close approximation to individual odontoblastic processes. A small area of dentin (D) is located in the upper left. $\times 6800$.

5 Sixty days. A capillary located in the basal portion of the odontoblastic layer exhibits several fenestrations (outlined box) which appear in the thin segment of the endothelial cell (EC). A thin process of a pericyte (PC) encloses the thin endothelial wall of the capillary in which the fenestrations are located. $\times 13,600$.

5a This enlargement of the outlined area of figure 5 illustrates a series of intracellular fenestrations (arrows) in the capillary wall which is separated from a thin process of an investing pericyte (PC) by a thin basement lamina. $\times 35,000$. 

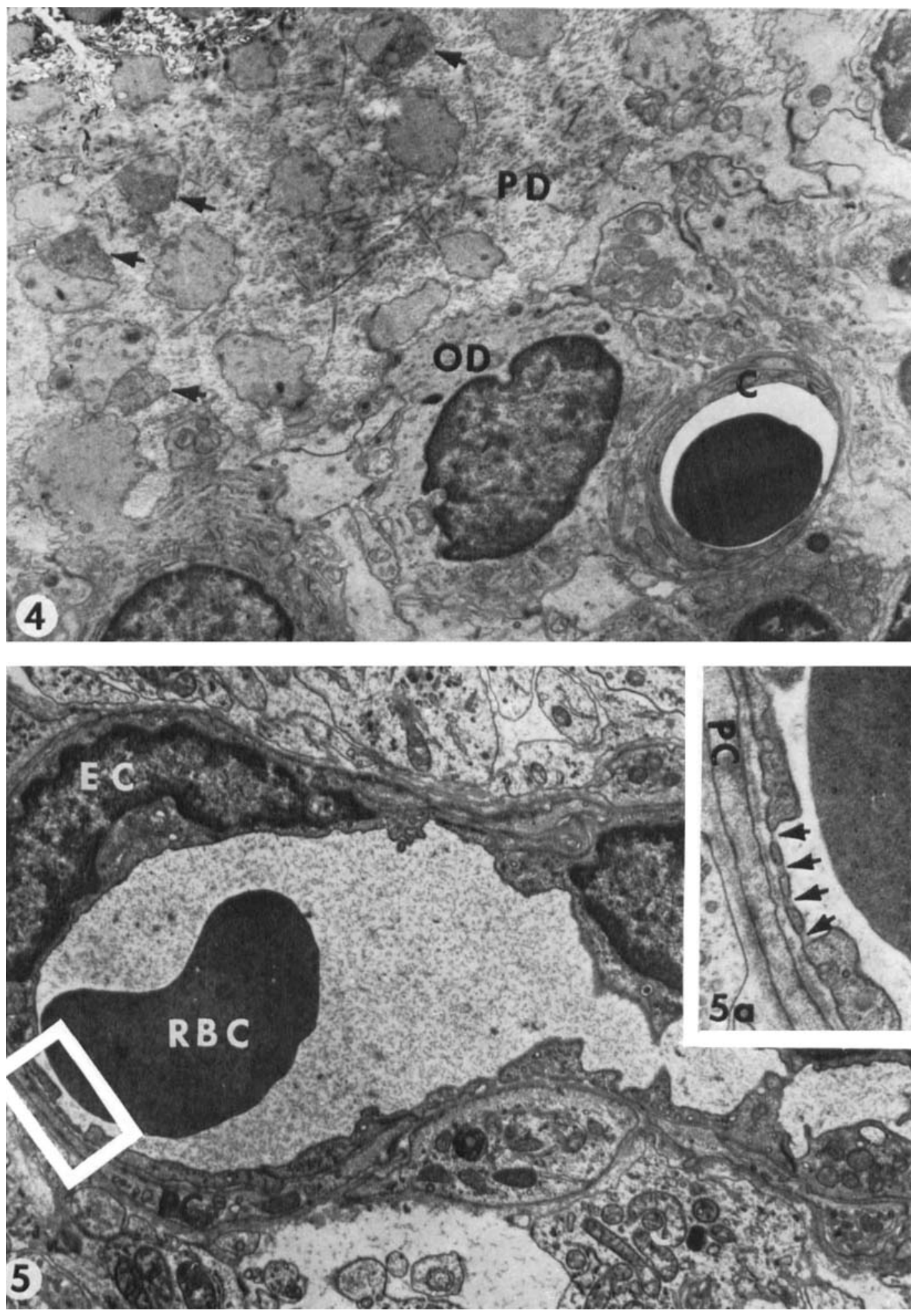
PLATE 4

EXPLANATION OF FIGURES

6 Eighty days. A capillary is located within predentin (PD) and is separated from the odontoblasts (OD) by a thin layer of predentin. An area of dentin (D) is immediately adjacent to the capillary wall in the lower left. The capillary lumen (CL) is present and contains several red blood cells ( $R B C$ ). The capillary exhibits fenestrations along a thin segment of endothelial wall. $\times 19,000$.

6a This area is an enlargement of the outlined area of figure 6 in which several intracellular fenestrations appear in the capillary wall (arrows). $\times 36,000$. 


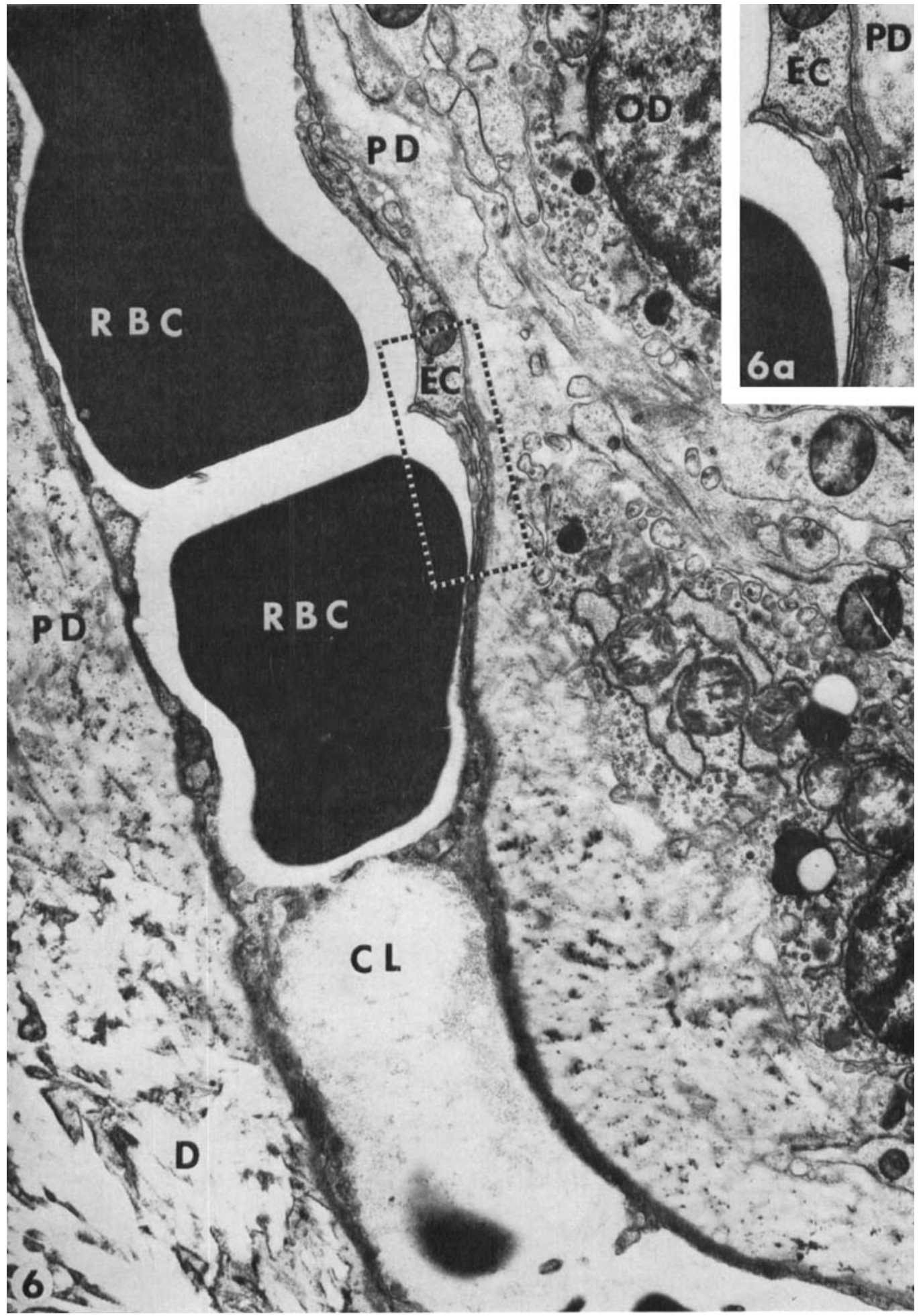


PLATE 5

EXPLANATION OF FIGURE

7 Eighty days. A capillary located immediately subjacent to the odontoblastic layer (OD) exhibits numerous fenestrations in the thin endothelial wall. The arrows are used to indicate those fenestrations in which a distinct diaphragm is observed. The capillary is completely invested by a distinct basement lamina, and isolated processes of pericytes $(\mathrm{PC})$ appear outside the lamina. $\times 27,500$. 


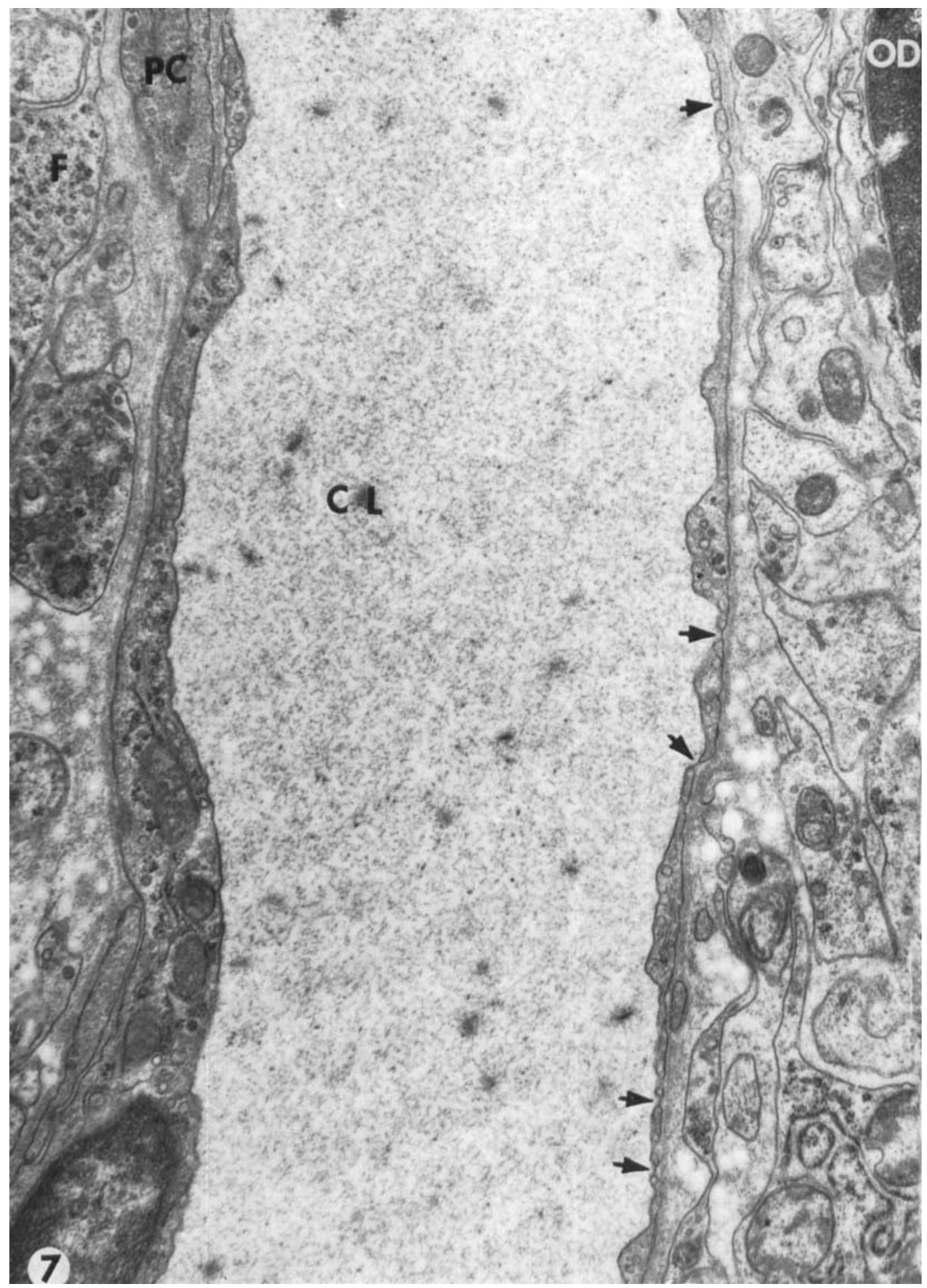

